\title{
A Novel UWB Antenna for a Broadcasting Television System
}

\author{
Euclides L. Chuma
}

Yuzo lano

Leonardo L. Bravo Roger

Silvio R. Messias de Carvalho 


\title{
A Novel UWB Antenna for a Broadcasting Television System
}

\author{
Euclides L. Chuma, Yuzo Iano, Leonardo L. Bravo Roger, Silvio R. Messias de Carvalho
}

\begin{abstract}
An ultra-wideband (UWB) discone antenna with an omnidirectional radiation pattern is proposed in order to be used in a broadcasting television system. It is an ultra-wideband antenna with an omnidirectional radiation pattern, using a single antenna to receive $\mathrm{TV}$ signals from several transmitting stations across various geographic locations. The UWB antenna proposed in this study covers a frequency range of $0.32-1.65 \mathrm{GHz}$ with a gain of $1.7 \mathrm{~dB}$. It operates in both conditions: indoor and outdoor.
\end{abstract}

Index Terms-antenna, UWB, TV, broadcasting, television, ultra-wideband.

\section{INTRODUCTION}

$\mathrm{T}$ ELEVISION broadcasting stations are spread across many locations. Therefore, the reception of TV signals by using only one directional antenna is not an easy task. To receive all the nearby signals, it is necessary to use several directional antennas. This fact makes such a system complex and expensive to implement. Besides, the reception system is sensible to signal loss owing to the use of external components such as mixers that experience insertion loss.

The use of an antenna with an omnidirectional radiation pattern could potentially provide a solution in a situation where it is necessary to receive signals from all directions. In this case, the antenna must also be able to receive these signals over a wide frequency range. For example, in Brazil, digital television (DTV) operates mainly in the UHF band between 470-800 $\mathrm{MHz}$ with a bandwidth of $6 \mathrm{MHz}$, as shown in Table I [1].

This paper proposes the use of a discone antenna. This paper presents the design, simulation, implementation and evaluation of that antenna. We chose a discone antenna because it has an omnidirectional radiation pattern and exceptional wideband [2] [3].

In this work, we study the discone antenna with an omnidirectional radiation pattern that covers the frequency range of 0.32-1.65 GHz, thus it is an UWB antenna. Over time, UWB has become a widely adopted term. Federal Communications Commission (FCC) rules [4] state the UWB band when fractional bandwidth is equal to or greater than 0.20 . The fractional bandwidth is given as follows:

E. L. Chuma is a Master Science Candidate at the State University of Campinas, and a researcher at the Laboratory of Visual Communications (email: euclides.chuma@ieee.org).

$\mathrm{Y}$. Iano, $\mathrm{PhD}$, is a professor and coordinator of the Laboratory of Visual Communications at the State University of Campinas (e-mail: yuzo@decom.fee.unicamp.br) fractional bandwidth $=2\left(f_{H}-f_{L}\right) /\left(f_{H}{ }^{+f_{L}}\right)$

Where, $f_{H}$ is the upper boundary frequency and $f_{L}$ is the lower boundary frequency. The bandwidth is equal to or greater than $500 \mathrm{MHz}$, regardless of the fractional bandwidth.

TABLE I

UHF DTV CHANNEL ASSIGNMENTS IN BRAZIL

\begin{tabular}{|c|c|c|c|}
\hline Channel & $\begin{array}{l}\text { Frequency } \\
(\mathrm{MHz})\end{array}$ & Channel & $\begin{array}{l}\text { Frequency } \\
(\mathrm{MHz})\end{array}$ \\
\hline 14 & $470-476$ & 43 & $644-650$ \\
\hline 15 & $476-482$ & 44 & $650-656$ \\
\hline 16 & $482-488$ & 45 & $656-662$ \\
\hline 17 & $488-494$ & 46 & $662-668$ \\
\hline 18 & $494-500$ & 47 & $668-674$ \\
\hline 19 & $500-506$ & 48 & $674-680$ \\
\hline 20 & $506-512$ & 49 & $680-686$ \\
\hline 21 & $512-518$ & 50 & $686-692$ \\
\hline 22 & $518-524$ & 51 & $692-698$ \\
\hline 23 & $524-530$ & 52 & $698-704$ \\
\hline 24 & $530-536$ & 53 & $704-710$ \\
\hline 25 & $536-542$ & 54 & $710-716$ \\
\hline 26 & $542-548$ & 55 & $716-722$ \\
\hline 27 & $548-554$ & 56 & $722-728$ \\
\hline 28 & $554-560$ & 57 & $728-734$ \\
\hline 29 & $560-566$ & 58 & $734-740$ \\
\hline 30 & $566-572$ & 59 & $740-746$ \\
\hline 31 & $572-578$ & 60 & $746-752$ \\
\hline 32 & $578-584$ & 61 & $752-758$ \\
\hline 33 & $584-590$ & 62 & $758-764$ \\
\hline 34 & $590-596$ & 63 & $764-770$ \\
\hline 35 & $596-602$ & 64 & $770-776$ \\
\hline 36 & $602-608$ & 65 & $776-782$ \\
\hline 38 & $614-620$ & 66 & $782-788$ \\
\hline 39 & $620-626$ & 67 & $788-794$ \\
\hline 40 & $626-632$ & 68 & $794-800$ \\
\hline 41 & $632-638$ & & \\
\hline 42 & $638-644$ & & \\
\hline
\end{tabular}

L. L. Bravo-Roger, $\mathrm{PhD}$, is a professor of the School of Technology at the State University of Campinas (e-mail: leobravo@ft.unicamp.br)

$\mathrm{S}$. Messias, $\mathrm{PhD}$, is a researcher of the Laboratory of Visual Communications at the State University of Campinas (e-mail: srcmessias@gmail.com). 


\section{ANTENNA DESIGN}

It is possible to analyze the discone antenna as a modification of the biconical antenna in which a disk replaces a cone [2]. The antenna feed is a coax located in the center of the cone that connects the outer shield to the lower cone. Besides, we connect the disk to the coax center conductor [3]. Fig. 1 shows a discone antenna with coaxial feed.

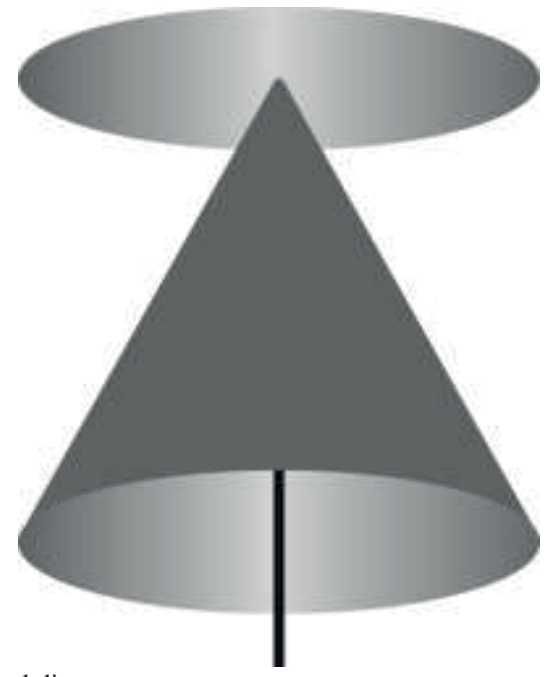

Fig. 1. A typical discone antenna.

The wide impedance bandwidth and dipole-like pattern occur because the discone antenna uses a biconical structure in which a diameter that varies smoothly at a fixed angle replaces the fixed wire diameter of the dipole [2].

A discone antenna for wideband impedance with acceptable frequency patterns can be designed using the dimensions shown in Fig. 2 such that $\mathrm{H}=0.7 \lambda, \mathrm{B}=0.6 \lambda, \mathrm{D}=0.4 \lambda, \theta_{\mathrm{h}}=25^{\circ} \mathrm{e} \delta<<$ $\mathrm{D}$, where $\lambda$ is the wavelength of the operating frequency [2] [5].

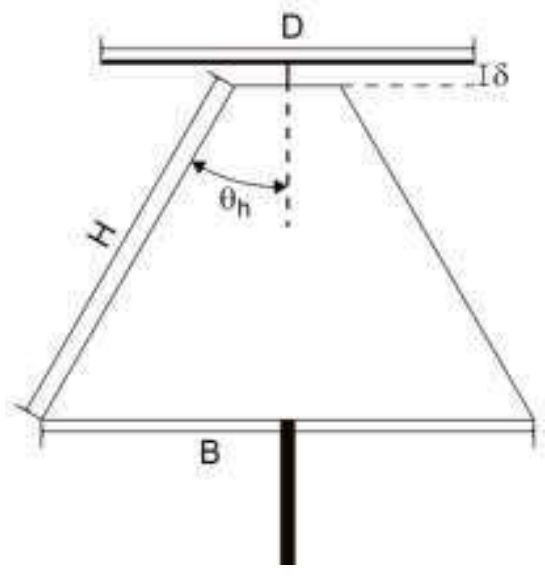

Fig. 2. Typical dimensions in the discone antenna.
We can improve the accuracy of the discone antenna by adjusting the antenna dimensions. We performed the antenna simulations using a full wave simulator Ansoft HFSS.

The discone antenna studied in this paper utilized the dimensions given in Fig. 3. We present the construction of the discone antenna in Fig. 4. A copper foil of $0.1 \mathrm{~mm}$ thickness was used to make the cone; the disk was made from single-sided FR-4 pcb with $\varepsilon_{\mathrm{r}}=4.4$ and a thickness of $1.6 \mathrm{~mm}$. Therefore, to obtain the doubled dimensions of $\delta=3.2 \mathrm{~mm}$, we used the following two disks of FR-4 pcb: the copper top disk had a diameter of $160 \mathrm{~mm}$ and the smaller non-copper bottom disk had a diameter of $40 \mathrm{~mm}$.

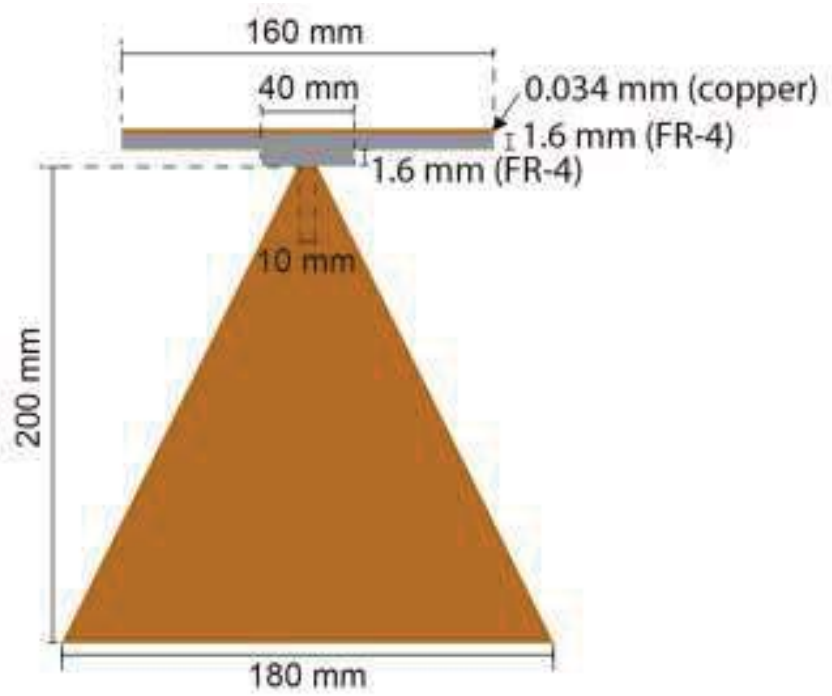

Fig. 3. Dimensions used in the discone antenna of this work.

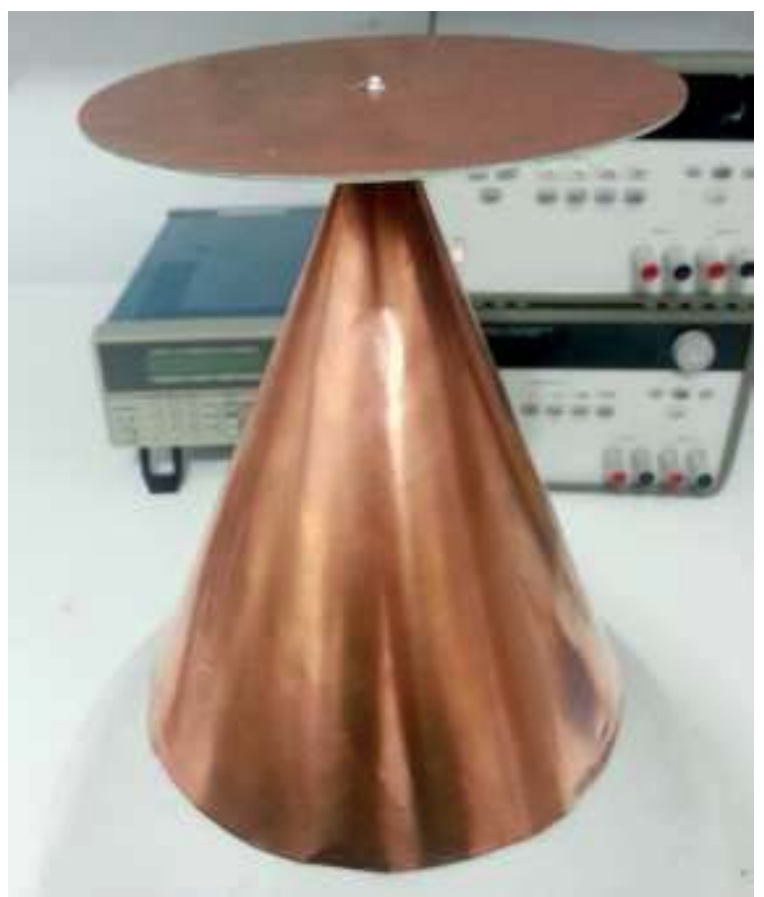

Fig. 4. Discone antenna construction. 
Fig. 5 shows the $\mathrm{S}_{11}$ parameters simulated and measured with a HP 8714B vector network analyzer.

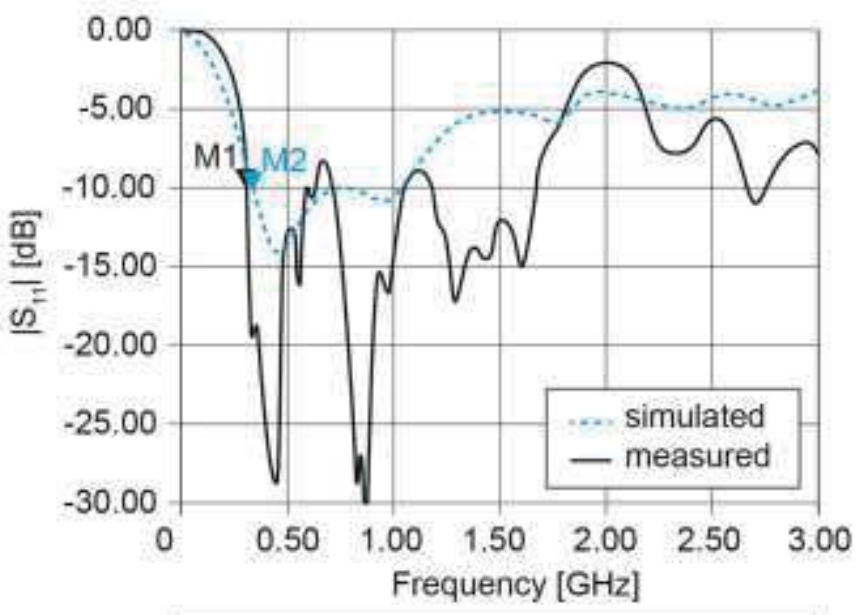

Fig. 5. Simulated and measured $S_{11}$ of the proposed antenna.

Fig. 6 shows the simulated radiation pattern. Fig. 7 shows the simulated 3D radiation pattern.
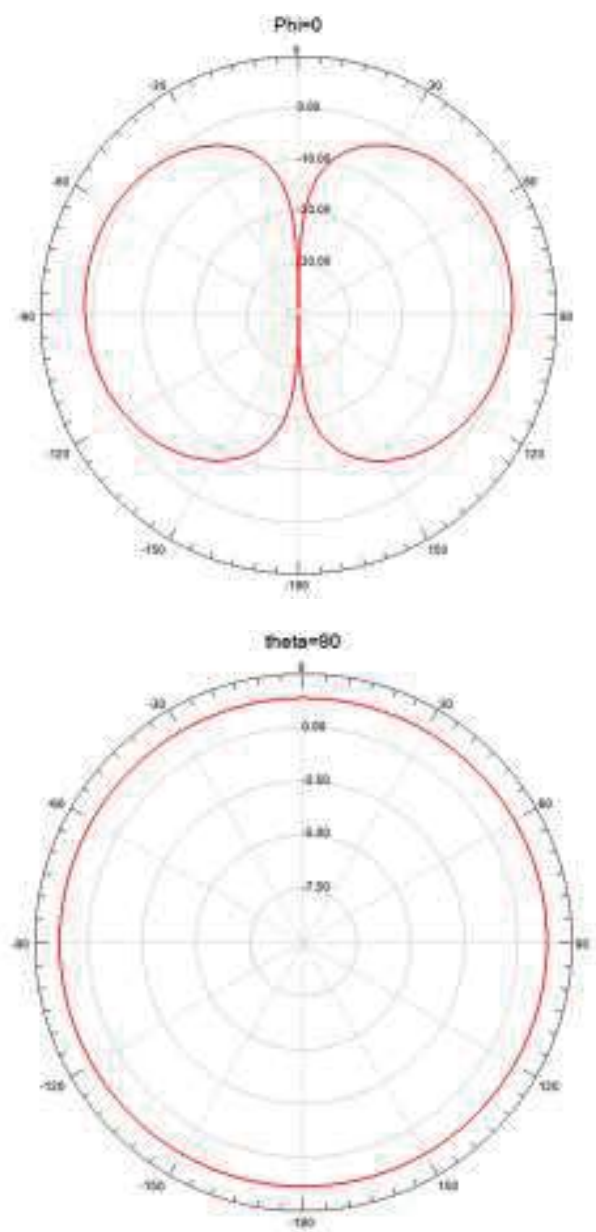

Fig. 6. The simulated radiation pattern.

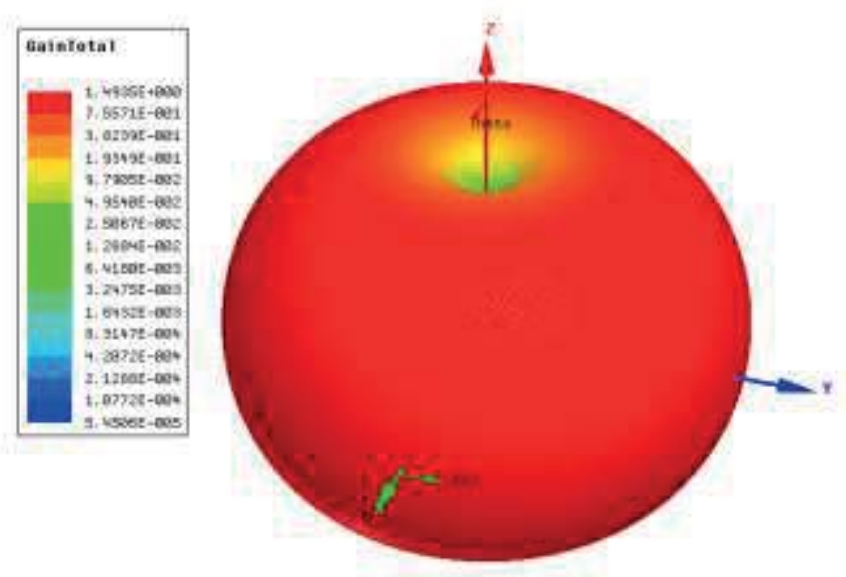

Fig. 7. The simulated 3D radiation pattern.

The Jsurf field vector at a center frequency of $635 \mathrm{MHz}$ is shown in Fig. 8.

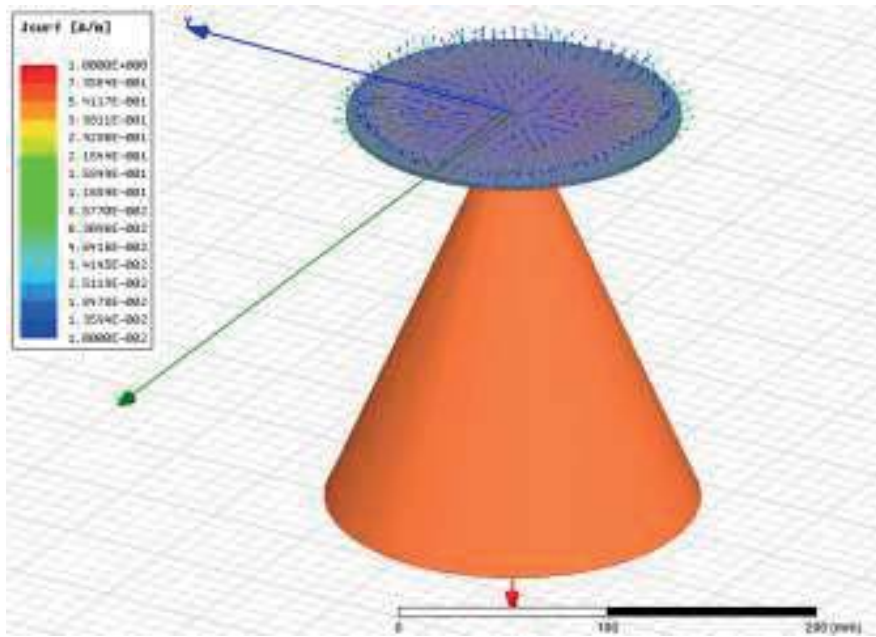

Fig. 8. Simulated Jsurf field vector of the proposed antenna.

Fig. 9 shows the discone antenna working with television. A balun matching transformer is used.

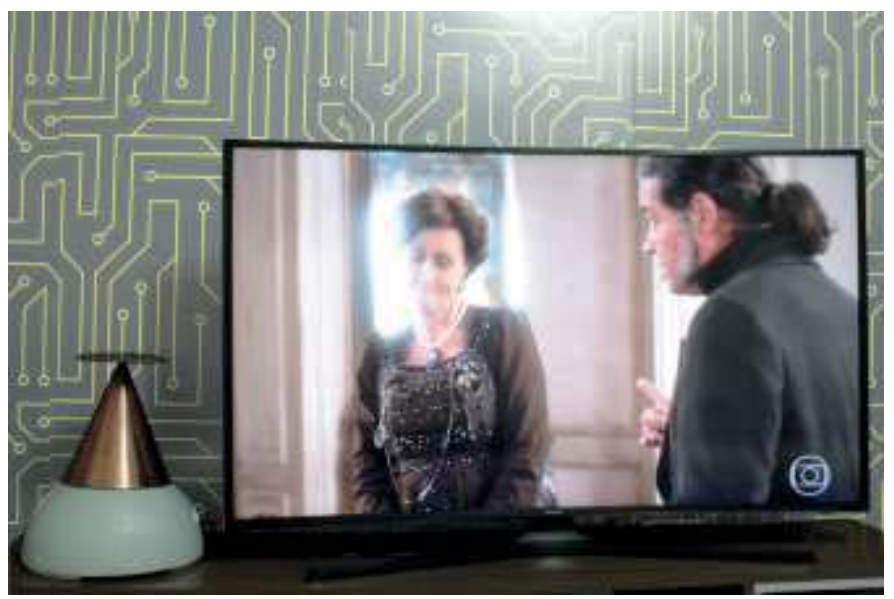

Fig. 9. A discone antenna working with a television. 


\section{CONCLUSIONS}

We developed and tested an UWB omnidirectional discone antenna that was capable of operating over a frequency range of $0.32-1.65 \mathrm{GHz}$ with a gain of $1.7 \mathrm{~dB}$. The proposed antenna works in both conditions, namely indoors and outdoors. This research presents a proven qualitative agreement between the experimental results and the numerical simulations. The small differences are owing to effects caused by parasitic capacitances and inductances and by adapters and connectors, not considered in the simulations.

\section{REFERENCES}

[1] ANATEL - Agência Nacional de Telecomunicações. Resolução nº583 de 27 de março de 2012. Available:

http://www.anatel.gov.br/legislacao/resolucoes/2012/146-resolucao-583

[2] W. L. Stutzman, G. A. Thiele, "Antenna Theory and Design", 2nd ed., John Wiley \& Sons Inc., 1998, pp. 243-246.

[3] T. A. Milligan, "Modern Antenna Design", 2nd ed., John Wiley \& Sons Inc., 2005, pp. 249-250.

[4] G. Breed. "A Summary of FCC Rules for Ultra Wideband Communications", High Frequency Electronics, 2005 Summit Technical Media, pp. 42

[5] J. J. Nail, "Designing Discone Antennas", Electronics, v. 26, pp. 167-169, aug. 1953.

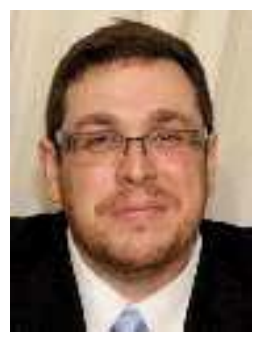

Euclides L. Chuma earned a degree in Mathematics from UNICAMP and graduate degree in Network and Telecommunications Systems in the INATEL. He is currently studying MSc in Electrical Engineering at UNICAMP, SPBrazil. He works as a software engineer in the private sector, and his research interests are Antennas, Wireless Power Transfer, Software Defined Radio and Cognitive Radio.

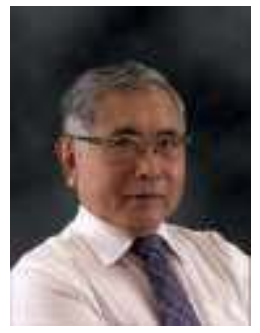

Yuzo Iano, $\mathrm{PhD}$, is the head and founder of the Laboratory of Visual Communications since 1972. He obtained his B.Sc (1972), M.Sc (1974) and PhD (1986) in Electrical Engineering at University of Campinas, SP-Brazil. Research Interests: Digital Signal Processing (images/audio/video), Digital TV, 4G (LTE) and 5G Cellular Networks, Pattern Recognition, Smart Cities, Smart Grid, Internet of Things.

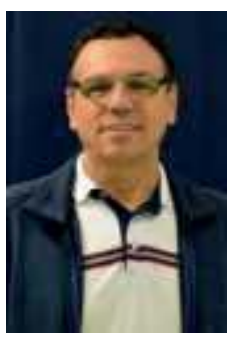

L. L. Bravo-Roger received the B. S. and M.Sc. degree in Telecommunication Systems from University of Oriente (UO), Santiago de Cuba, in 1985 and 1998, respectively, and the $\mathrm{Ph} . \mathrm{D}$. degree in Electric Engineering from Faculty of Electrical and Computer Engineering, University of Campinas (UNICAMP), Campinas, São Paulo, Brazil, in 2003. Since 2004, he is with School of Technology of UNICAMP, Limeira, São Paulo, Brazil. His research activities are in the areas of RF and microwave technologies and radar sensing systems and Wireless Sensor Networks.

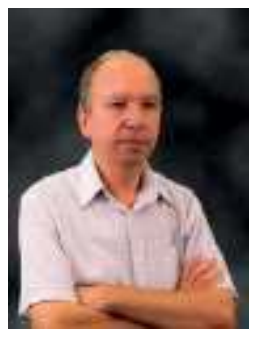

Silvio R. Messias de Carvalho, $\mathrm{PhD}$, obtained his B.Sc degree in Electrical Engineering at UNICAMP (1994). Holds a MSc degree (2007) and a $\mathrm{PhD}$ degree (2013) in Electrical Engineering from UNICAMP as well. Research Interests: Audio and video for digital TV, broadcast engineering, digital TV engineering, RF systems, mobile TV, antennas and Energy

Efficiency 